\title{
The Definition of the Parameters of Innovative Transport and Technological Equipment for the In-Road Pavement Recycling, Using the Method of The Analysis of Fourth Coordinate of The Process
}

\author{
Nikolai Seliverstov ${ }^{1}$, Gennadiy Kustarev ${ }^{1}$, Konstantin Mandrovskiy ${ }^{1}$, Dilyara Izmailova ${ }^{1}$, \\ and Svetlana Glagoleva ${ }^{1}$ \\ ${ }^{1}$ Moscow Automobile and Road Construction State Technical University (MADI), 64 Leningradsky \\ prosp., 125319, Moscow, Russia
}

\begin{abstract}
The features of the workflow of innovative transport and technological machines with non-waste technology, multi-purpose machines, recyclers and others similar are described in the article. The calculation methodology for determining the optimal parameters of machines and modes of operation, based on method of the analysis of fourth coordinate (duration) of the operating cycle, is presented. Dependences for determination of the power drive units of recycler are given. The procedure allows optimizing the parameters of the individual equipment units and of the entire recycler machine is described.
\end{abstract}

\section{Introduction}

The use of innovative technology with optimal parameters is a significant reserve of intensification of the construction. Work is developing on the creation of innovative technology in the following areas: the creation of self-managed or smart machines; the creation of machines with a non-waste technology works (recycler); the establishment of multi-purpose equipment.

Recycler is one of the most efficient vehicles for the construction, repair and reconstruction of road's asphalt and concrete pavements. The most widely used recyclers work on cold recycling technology, Fig. 1.

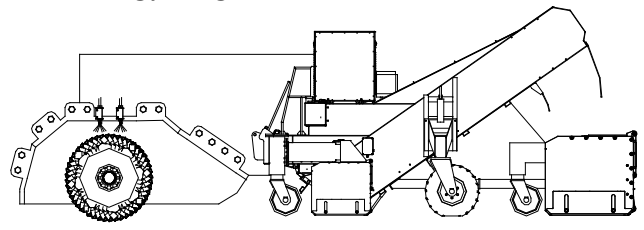

Fig. 1. The road recycler complex system

* Corresponding author: seliverstov_nd@inbox.ru 
The whole complex of technological works: loosening and granulating the material of damaged pavement, the injection of binding and stabilizing materials such as bitumen emulsion, foamed bitumen or cement-water emulsion, mixing of the material with the added binders, the new mixture paving and compaction - is performed by one machine. Recycler is a complex system, consisting of a number of equipment units, each of which performs a specific operation. Collectively equipment units perform the duty cycle of the recycler machine.

It should be noted that the existing methods of construction and rehabilitation of roads on the basis of the use of a set of single-purpose machines practically exhausted its ability to achieve the objectives related to improving the quality and pace of road construction. The usage of machines such recycler, working on non-waste technology, is one of the promising areas of intensification of road construction.

Definition of the parameters should be considered for optimal RAP (recycled asphalt pavement) and new hot, cold or warm asphalt mix composition and optimal pavement quality requirements [9].

Method for determining and selecting the optimum settings, depending on the operating conditions require a system of indicators that provides an objective evaluation of the solution.

Existing indicators to measure the effectiveness of the machine: the maximum performance $\left(\Pi_{\max }\right)$, minimum energy intensity and material requirements $\left(m_{y d}\right)$, the generalized index $\left(\Pi_{N m}\right)$, the energy saturation $\left(N_{e n}\right)$, the unit price $\left(C_{y d}\right)$ and other have following disadvantages: a) There is not generalized model that allocates in its structure, diversity and mutual influence of technical and operational factors determining the conditions of operation; b) Not taken into account conflicting demands of a number of working operations to the technical parameters of machines. c) Working operation of the machine require high tractive effort and, therefore, machine weight, at a single movement, on the contrary; d) There are not methods for obtaining optimal solutions and synthesis of the results on the system of these machines.

Performance evaluation requires experimental studies with real equipment, in the design phase of such sample yet.

The duration of the working operations of the machine is determined experimentally. The existing system of indicators and calculation methods require development and additions.

The effectiveness of object is set with the same reliability of the compared machines at the design stage. Reliability indices are evaluated in subsequent phases of the creation of the machine.

\section{The method of the analysis of fourth coordinate of the process}

A mathematical model of the fourth coordinate (duration) of the working cycle of the machine is proposed to be used as a summary measure of the efficiency of the machine [1].

This model is generalized and includes a complex of mathematical models: forces of resistance, tractive effort, and energy characteristics of the object.

Existing performance indicators (productivity, output per worker, consumption, material consumption, price per unit of output) are functions of the fourth coordinates (duration) of the operating cycle of the machine $\left(t_{c}\right)$. These parameters are optimal at the lowest value of the indicator $\left(t_{c}\right)$.

The fourth coordinate $\left(t_{c}\right)$ (duration) workflow is an important indicator for assessing the effectiveness of the machine [1]. Figure $\left(t_{c}\right)$ avoids the above-mentioned shortcomings in the evaluation of machine. 
The duration of the working process (operations) $\left(t_{c}\right)$ is regarded as the coordinates of the fourth process (operation cycle) along with the linear referencing process - length, width, height.

At the design stage, the value of the fourth coordinate (duration) of the operating cycle is formed as a ratio of mathematical models of the work of resistance forces, while performing the operation to mathematical models, of the power that can be realized by the machine to perform the corresponding operation.

For machines with a serial execution of the operations cycle times $\left(t_{c}\right)$, determined by the formula:

$$
\begin{aligned}
& \mathrm{t}_{c}=\sum_{1}^{\mathrm{n}} \mathrm{t}_{\mathrm{i}} \rightarrow \min , \\
& \mathrm{t}_{c}=\sum_{1}^{\mathrm{n}} \frac{\mathrm{i}}{\mathrm{N}_{\mathrm{i}}} \rightarrow \min
\end{aligned}
$$

where $t_{c}$ - time step (cycle) of the machine, sec; $t_{i}$ - time individual working operations of the machine, sec; $n$ is the number of operations performed by the machine during the operating cycle; $A_{i}$ is a mathematical model that defines the work of resistance forces when executing the corresponding operation, $[\mathrm{Nm}] ; N_{i}$ - mathematical model, which determines the power that can be realized by the machine to perform operations, $[\mathrm{Nm} / \mathrm{s}]$.

For a machine with parallel execution of operations, with a combination of (simultaneous execution) business operations - the condition of combining operations is determined by the equality of durations combine operations $t_{i}=t_{j}[1]$.

The optimal value of the main technical parameter (the mass $m$ of cardinality $N$, energy per mass $\mathrm{N} / \mathrm{m}$, etc.) are determined on the basis of dependencies:

$$
\frac{\partial \mathrm{t}_{c}}{\partial \mathrm{m}}=0, \frac{\partial \mathrm{t}_{c}}{\partial \mathrm{N}}=0
$$

etc. such relationships.

Optimization of parameters is carried out by analyzing the coordinates of the fourth process of sequentially: 1 . Determined technical concept of the object; 2 . Place the machine is determined in the process, the mode of movement - steady, unsteady; 3 . The sequence of operations is established, their possible combination and structural model the coordinates of the fourth process; 4. A mathematical model is formed of the duration of each operation; 5. The General mathematical model of the working cycle is formed; 6 . A simplified model is made for a steady-state process; 7. Is Performed functional analysis and parameter optimization.

Mathematical models of the fourth coordinates of the processes are described in work [1].

The method allows to solve optimization problems in the design and operation of equipment.

The optimal parameters, the performance of the unit and the main technical and economic indicators of the process, including the cost of products are established in the design phase of an innovative technology.

The task is solved for the operational phase on the market or in the park of the enterprise on the basis of the optimum machine $\left(\mathrm{m}_{\mathrm{opt}}\right),(\mathrm{N} / \mathrm{m})$ opt parameters ensuring the conditions specified in the work to maximum effect [1].

It should be emphasized that the most accessible and least cheap method of intensification of transport and technological machines and earth moving equipment is the 
choice available on the market or in the park of the enterprise machines with optimal parameters depending on the operating conditions of the consumer.

Between mass, capacity and other parameters of self-propelled machines are functional relations of similarity systems [1]. On the basis of similarity transformations of the optimal solution obtained by the analysis method of the fourth coordinates, generalized system of such innovative systems.

\section{The formation of dependencies that define the relationship between the main parameters of such objects technology}

Optimal machine parameters obtained by the analysis method of the fourth coordinates, can be generalized to similar technology and similar conditions $[1,2,8]$.

A generalization of the optimal solution receives on the basis of consideration of the machines in the form of such object in a group of similar machines that perform similar processes. Association analysis of mathematical models of the fourth coordinates of the operating cycle and the similarity theory allows to solve two tasks: to obtain an optimal result by minimizing the mathematical model of the fourth coordinates of the operating cycle and to generalize the result to other similar facilities equipment and conditions of operation.

Correlation between parameters of transport and technological machines are determined on the basis of equality, similarity criteria established in the process of interaction of the working body of the machine with the environment. This allows to obtain more simple dependence.

Table 1. Formula to determine the technical parameters of transport and technological, digging and road machines

\begin{tabular}{|c|c|c|c|c|c|}
\hline \multirow{2}{*}{ Calculated parameter } & \multicolumn{5}{|c|}{ Defines the parameters } \\
\cline { 2 - 6 } & $\mathbf{N}$ & $\mathbf{T}$ & $\mathbf{m}$ & $\mathbf{q}$ & $\mathbf{I}$ \\
\hline Power N & - & $\mathrm{k} 1 \cdot \mathrm{T}$ & $\mathrm{k} 2 \cdot \mathrm{m}$ & $\mathrm{k} 3 \cdot \mathrm{q}$ & $\mathrm{k} 4 \cdot 13$ \\
\hline Traction force T & $\mathrm{k} 5 \cdot \mathrm{N}$ & - & $\mathrm{k} 6 \cdot \mathrm{m}$ & $\mathrm{k} 7 \cdot \mathrm{q}$ & $\mathrm{k} 8 \cdot 13$ \\
\hline Mass $\mathrm{m}$ & $\mathrm{k} 9 \cdot \mathrm{N}$ & $\mathrm{k} 10 \cdot \mathrm{T}$ & - & $\mathrm{k} 11 \cdot \mathrm{q}$ & $\mathrm{k} 12 \cdot 13$ \\
\hline $\begin{array}{c}\text { The capacity of the main bucket } \\
\mathrm{q}\end{array}$ & $\mathrm{k} 13 \cdot \mathrm{N}$ & $\mathrm{k} 14 \cdot \mathrm{T}$ & $\mathrm{k} 15 \cdot \mathrm{m}$ & - & $\mathrm{k} 16 \cdot 13$ \\
\hline Linear size li & $\mathrm{k} 17 \cdot \mathrm{N} 1 / 3$ & $\mathrm{k} 18 \cdot \mathrm{T} 1 / 3$ & $\mathrm{k} 19 \cdot \mathrm{m} 1 / 3$ & $\mathrm{k} 20 \cdot \mathrm{q} 1 / 3$ & - \\
\hline $\begin{array}{c}\text { Bucket capacity optional } \\
\text { equipment qд }\end{array}$ & $\mathrm{k} 21 \cdot \mathrm{N}$ & $\mathrm{k} 22 \cdot \mathrm{T}$ & $\mathrm{k} 23 \cdot \mathrm{m}$ & $\mathrm{k} 24 \cdot \mathrm{q}$ & $\mathrm{k} 25 \cdot 13$ \\
\hline Load mгp & $\mathrm{k} 26 \cdot \mathrm{N}$ & $\mathrm{k} 27 \cdot \mathrm{T}$ & $\mathrm{k} 28 \cdot \mathrm{m}$ & $\mathrm{k} 29 \cdot \mathrm{q}$ & $\mathrm{k} 30 \cdot 13$ \\
\hline Working speed $\mathrm{v}=1,0 \ldots 1,5 \mathrm{~m} / \mathrm{s}$ & \multicolumn{5}{c}{$\mathrm{v} \approx$ const } \\
\hline
\end{tabular}

The formula of similarity between the main technical parameters is given in table. 1 . The formula to calculate the coefficients of proportionality are given in table. 2 .

The statistical relationships between the basic technical parameters confirms the similarity of transport and technological machines that have a similar technological purpose.

The proportionality coefficients are set by the parameters high current machines, taken as a reference, or parameters measured at the appropriate scale model of new technology, which shows high efficiency or set of analytical methods to minimize the fourth position of the working cycle of the machine. This parameter is assigned a code " 0 ".

The above material confirms the possibility for such systems, identifying a number of technical parameters of the main technical parameters, such as mass $\mathrm{m}$, and the corresponding dimension of similarity coefficient $k_{i}[1]$. 
Table 2. The coefficients of proportionality for such transportation and processing, earthmoving and road machine

\begin{tabular}{|c|c|c|c|c|c|}
\hline Coefficient & $\begin{array}{c}\text { Calculated } \\
\text { dependence }\end{array}$ & Coefficient & $\begin{array}{c}\text { Calculated } \\
\text { dependence }\end{array}$ & Coefficient & $\begin{array}{c}\text { Calculated } \\
\text { dependence }\end{array}$ \\
\hline $\mathrm{k} 1$ & $\mathrm{~N} 0 / \mathrm{T} 0$ & $\mathrm{k} 11$ & $\mathrm{~m} 0 / \mathrm{q} 0$ & $\mathrm{k} 21$ & $\mathrm{q} \partial 0 / \mathrm{N} 0$ \\
\hline $\mathrm{k} 2$ & $\mathrm{~N} 0 / \mathrm{m} 0$ & $\mathrm{k} 12$ & $\mathrm{~m} 0 / 103$ & $\mathrm{k} 22$ & $\mathrm{q} \partial 0 / \mathrm{T} 0$ \\
\hline $\mathrm{k} 3$ & $\mathrm{~N} 0 / \mathrm{q} 0$ & $\mathrm{k} 13$ & $\mathrm{q} 0 / \mathrm{N} 0$ & $\mathrm{k} 23$ & $\mathrm{q} \partial 0 / \mathrm{m} 0$ \\
\hline $\mathrm{k} 4$ & $\mathrm{~N} 0 / 103$ & $\mathrm{k} 14$ & $\mathrm{q} 0 / \mathrm{T} 0$ & $\mathrm{k} 24$ & $\mathrm{q} 20 / \mathrm{q} 0$ \\
\hline $\mathrm{k} 5$ & $\mathrm{~T} 0 / \mathrm{N} 0$ & $\mathrm{k} 15$ & $\mathrm{q} 0 / \mathrm{m} 0$ & $\mathrm{k} 25$ & $\mathrm{q} \partial 0 / 103$ \\
\hline $\mathrm{k} 6$ & $\mathrm{~T} 0 / \mathrm{m} 0$ & $\mathrm{k} 16$ & $\mathrm{q} 0 / 103$ & $\mathrm{k} 26$ & $\mathrm{mgr} 0 / \mathrm{N} 0$ \\
\hline $\mathrm{k} 7$ & $\mathrm{~T} 0 / \mathrm{q} 0$ & $\mathrm{k} 17$ & $10 / \mathrm{N} 01 / 3$ & $\mathrm{k} 27$ & $\mathrm{mgr} 0 / \mathrm{T} 0$ \\
\hline $\mathrm{k} 8$ & $\mathrm{~T} 0 / 103$ & $\mathrm{k} 18$ & $10 / \mathrm{T} 01 / 3$ & $\mathrm{k} 28$ & $\mathrm{mgr} 0 / \mathrm{m} 0$ \\
\hline $\mathrm{k} 9$ & $\mathrm{~m} 0 / \mathrm{N} 0$ & $\mathrm{k} 19$ & $10 / \mathrm{m} 01 / 3$ & $\mathrm{k} 29$ & $\mathrm{mgr} 0 / \mathrm{q} 0$ \\
\hline $\mathrm{k} 10$ & $\mathrm{~m} 0 / \mathrm{T} 0$ & $\mathrm{k} 20$ & $10 / \mathrm{q} 01 / 3$ & $\mathrm{k} 30$ & $\mathrm{mgr} 0 / 103$ \\
\hline
\end{tabular}

Block diagrams of determining the parameters of innovative transport and technological machines by analyzing the fourth position and results of calculations are described in work [1].

\section{The dependences for determination the power and the efficiency of recycler}

Calculation of parameters and operating modes of the recycler is performed by analyzing the fourth coordinate of the process. The method of analysis of the fourth coordinate cycle duration, is proposed in Moscow Automobile and Road Construction University (MADI), Russian Federation [3-6].

The structural model of the fourth coordinate is made on the analysis of the whole process of recycler and of individual units. For recycler (Figure 1) structural model includes the performance of a number of process steps, each of which takes a certain length: the movement of the recycler as a complex system, loosening and pre-mixing of materials, mixing the material with stabilizing additives, milling operations, distribution of materials and loaded mixture pre-compaction.

Operations are carried out simultaneously with the movement of the recycler. Structural cycle model of recycler in conditions of optimum flow of the workflow is given equal duration of the operation:

$$
\mathrm{t}_{r s k}=\mathrm{t}_{1}=\mathrm{t}_{2}=\mathrm{t}_{3}=\mathrm{t}_{4}
$$

The complexity of the analysis of this model is the need to take into account an important feature of the course of operations. A number of private operations units occur sequentially or simultaneously.

The power required for the implementation of processes aggregates: milling unit, twoshaft mixer, the distributor and the compactor are determined for a given performance recycler, [7]. Total power for the drive of all units of the recycler is the sum of the values:

$$
\mathrm{N}_{\text {rsk }_{\Sigma}}=\mathrm{N}_{\text {rsk }}+\mathrm{N}_{\mathrm{f}}+\mathrm{N}_{\mathrm{sm}}+\mathrm{N}_{\text {rasp }}+\mathrm{N}_{\text {upl }}
$$

An important step in determining the optimal operation of the recycler is the analysis and comparison of the performance of individual units and recycler. The relationship between the performance is determined by a system of inequalities: 


$$
\Pi_{\text {rsk }} \leq \Pi_{\text {rsk }} \leq \Pi_{\mathrm{f}} \leq \Pi_{\mathrm{sm}} \leq \Pi_{\mathrm{rasp}} \leq \Pi_{\mathrm{upl}}
$$

A system performance equation, in sequence calculations, allows determining the optimal parameters for each of the units of the machine on the set: recycler performance, the technical parameters of the machine and the physical and mechanical properties of the developed material. The total capacity of the machine and the power of each unit is determined by way of example, for a given recycler performance and performance dependencies of each of the units [7, 1].

The performance of individual components is determined by the formulas considered in the work [7]. Recycler's performance can be set on the basis of the relationship:

$$
\Pi_{\mathrm{rsk}}=\mathrm{F}_{\mathrm{P}} \cdot \mathrm{V}_{\mathrm{p}} \cdot \mathrm{z}_{\mathrm{Z}} \cdot \mathrm{z}_{\mathrm{f}}, \Pi_{\mathrm{rsk}}={ }_{\mathrm{B}} \mathrm{P} \cdot \mathrm{V}_{\mathrm{p}} \cdot \mathrm{z}_{\mathrm{Z}} \cdot \mathrm{z}_{\mathrm{f}}
$$

Wherein $z_{z}$ - the number of teeth developing material; $z_{f}$ - the number of milling units, involved in the process; $F_{p}$ - The area of the element, separated from the cutter tooth array, $\mathrm{m}^{2} ; \boldsymbol{B}_{p}$ - the width of the surface to be treated, $\mathrm{m} ; V_{p}$ - The recycler feed speed, $\mathrm{m} / \mathrm{sec}$.

Detachable element area is determined:

$$
\mathrm{F}_{\mathrm{P}}=\mathrm{b} \cdot \mathrm{h}_{\mathrm{Z}}
$$

Wherein $h_{z}$ - an average feed per tooth cutter, $\mathrm{m}$.

The velocity is determined by the ratio of the recycler feed to the minimum time of submission, $\mathrm{m} / \mathrm{sec}$ :

$$
v_{\mathrm{f}}=\frac{\mathrm{h}_{\mathrm{z}}}{\mathrm{t}_{\text {Fmin }}},
$$

$h_{z}$ - An average feed per tooth cutter, $m$.

$t_{\text {Fmin }}$ - The minimum duration of the machine at a distance of filing, sec.

Velocity determination is reviewed in [7].

Recycler's performance in feed rate determined by the formula:

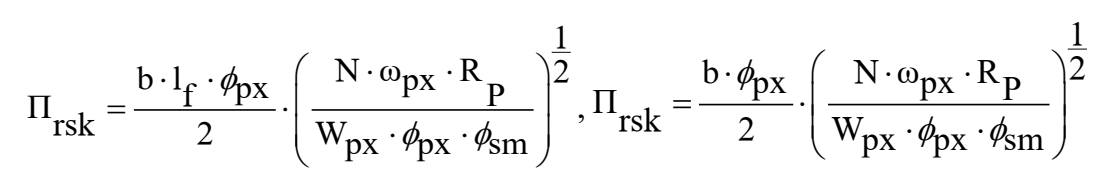

Determine the performance of individual units considered in [7]. Optimum recycler performance is given by (3).

Milling drum power determination is based on the formula $P_{r s k} \leq P_{f}$ and milling performance depending on the required performance recycler $P_{r s k}$

$$
\mathrm{N}_{\mathrm{f}}=\frac{4 \cdot \mathrm{P}_{\mathrm{rsk}}^{2} \cdot \mathrm{W}_{\mathrm{f}} \cdot v_{\mathrm{f}}^{2} \cdot \phi_{\mathrm{sm}}}{\omega_{\mathrm{f}} \cdot \mathrm{R}_{\mathrm{p}} \cdot v_{\mathrm{rsk}}^{2} \cdot \mathrm{b}^{2} \cdot \mathrm{z}_{\mathrm{z}}^{2} \cdot \phi_{\mathrm{px}} \cdot \eta^{2}}
$$

Wherein $P_{r s k}$ - defined recycler performance, $\mathrm{m}^{2} / \mathrm{s}$.

Further, similar to the power succession, the power of other units is determined.

Power-shaft mixer:

Screw distributor power:

$$
\mathrm{N}_{\mathrm{sm}}=2 \cdot \mathrm{P}_{r s k} \cdot \mathrm{C}_{\mathrm{sc}} \cdot \mathrm{D}_{1} \cdot \mathrm{k}_{\mathrm{tr}} \cdot \operatorname{tg} \alpha_{1} .
$$

$$
\mathrm{N}_{\mathrm{sh}}=2 \cdot \mathrm{P}_{r s k} \cdot \mathrm{C}_{\mathrm{Sc}} \cdot \mathrm{D}_{\mathrm{sh}} \cdot \mathrm{k}_{\mathrm{tr}} \cdot \operatorname{Cos} \alpha_{1} \cdot \operatorname{tg} \alpha_{1} .
$$


Tamper power:

$$
\mathrm{N}_{\mathrm{BB}}=\frac{\mathrm{C}_{\mathrm{Sc}} \cdot \mathrm{b} \cdot \mathrm{l}_{\mathrm{b}} \cdot \omega_{\mathrm{bb}} \cdot \mathrm{k}_{\mathrm{tr}} \cdot \mathrm{a}_{b b}}{2 \cdot \pi} .
$$

Power to the recycler drive units:

$$
N_{r s k} \geq \sum N_{\text {agr } i}
$$

Symbols adopted in text.

$\mathrm{W}_{\text {rsk }}$ - recycler and separate units resistance forces, $\mathrm{N}, \mathrm{N}-$ power, $\mathrm{Nm} / \mathrm{s}, \mathrm{v}-$ the working speed of the recycler, individual working equipment, $\mathrm{m} / \mathrm{s}, \mathrm{f}_{\mathrm{p}, \mathrm{x}}-$ the resistance to motion units, $1_{\mathrm{f}}$ - recycler feed per tooth cutters, $\mathrm{m}, \mathrm{P}$ - performance recycler separate units $\mathrm{m}^{3} / \mathrm{s}, \mathrm{m}^{2} / \mathrm{s}, \mathrm{C}_{\mathrm{sc}}-$ material grip forces, $\mathrm{N} / \mathrm{m}^{2}, \varphi-$ angular path milling in the tooth loosening, mixing, $\omega_{\mathrm{f}}-$ the circumferential speed of milling cutter $1 / \mathrm{s}, \mathrm{R}_{\mathrm{p}}$ - cutter radius, $\mathrm{m}, \mathrm{D}_{\mathrm{l}, \mathrm{sh}}-$ diameter blade mixer, auger, $\mathrm{m}, \mathrm{k}_{\mathrm{tr}}=(1+\mathrm{f})-$ which takes into account the friction coefficient of $1.15-135, \alpha_{1}$ - helix angle, hail, $a_{b b}$ - Tamper amplitude of the oscillations, m.

The procedure allows optimizing the parameters of the individual units and the entire recycler. The weight of individual units, the power of a drive system is determined by the number of units that make up the recycler. Optimal recycler performance is determined by optimization of individual units. Specific recycler unit price is determined by the system of inequalities, each of which is characterized by a specific value of the respective unit. This allows user to optimize the unit price of the final product through the optimization of each of the units, leaving no need to change the value of the specific unit cost of the final product.

The creation of method of calculation and optimization of multi-functional modular system as a single unit allows to determine the effectiveness of a multi-purpose machine, depending on the operating conditions. This technique allows to predict the performance of individual modules and the entire unit performance. The above provisions will contribute to the foundations of the design and organization of technology production for the rapid construction and reconstruction of roads of non-waste technology.

\section{Conclusions}

1. Optimal technical parameters of transport and technological machines can be installed analysis methods, minimizing the mathematical model of the fourth coordinate (duration) workflow.

2. The method set parameters and mathematical models of self-managed modes (IP) technology.

3. The method allows to determine the parameters and modes of operation of units with non-waste technology of work (recycler) and multi-purpose machines with working bodies

4. Optimal solution obtained by the methods of analysis, a mathematical model to minimize the fourth coordinate (duration) of the working process is summarized by these transformations on these objects are performing similar processes.

5. Method analysis, minimization of the mathematical model of the fourth coordinate (duration) workflow justifies the position that cars with certain technical parameters provide a high technical effect in certain operating conditions. 


\section{References}

1. V.I. Balovnev, Optimization and selection of innovative systems and processes of transport and technological machines. -M .: Tehpoligraftsentr, 320 p. (2014)

2. V.I. Balovnev, S.N.Glagolev, R.G. Danilov, etc., Excavating and earthmoving machines: Proc. manual for schools, Belgorod Univ BGTU, 401 p. (2012)

3. V.I. Balovnev, S.N. Glagolev, R.G. Danilov, etc ., Handling and sealing machines: Proc. manual for schools, Belgorod Univ BGTU, 464 p. (2012)

4. V.I. Balovnev, R.G. Danilov, A.G. Savelyev, Machines for maintenance of urban and highways: Maintenance of roads in summer: Proc. manual for schools. -M .: Tehpoligraftsentr, 333 p. (2013)

5. V.I. Balovnev, R.G. Danilov, A.G. Savelyev, Machines for maintenance of urban and highways: Maintenance of roads in winter: Proc. manual for schools. $-\mathrm{M}$.: Tehpoligraftsentr, 343 p. (2013)

6. V.I. Balovnev, Evaluation of innovative proposals in the road and construction equipment: Textbook, MADI (STU). - M., 100 p. (2008)

7. N.D. Seliverstov, Methods for calculating the efficiency of modern recyclers and technological complexes of equipment for the construction and reconstruction of roads, Bulletin of the development of science and education, 3, pp. 68-72 (2014)

8. V.I. Balovnev, R.G. Danilov, N.D. Seliverstov, The analysis of parameters and operating modes of the main systems recycler, Building and road machines, 10, pp. 4548 (2014)

9. N.D. Seliverstov, Selection of asphalt-concrete mixed compositions in cold recycling of road surfaces, Polymer Science. Series D, 1, pp. 106-109 (2016) 